\title{
Estudios
}

\section{¡El compliance llegó para quedarse! Qué debe saber el empresario acerca del programa de cumplimiento y el poder corporativo}

\section{Compliance is here to stay! What an entrepreneur should know about the compliance program and corporate power}

\section{Hoover Wadith Ruiz Rengifo*}

- Recepción: 30/03/2020 • Aprobación:23/06/2020 • Publicación: 31/08/2020

Para citar este artículo

Ruiz Rengifo, H. W. (2020). ¡El compliance llegó para quedarse! Qué debe saber el empresario acerca del programa de cumplimiento y el poder corporativo. Dos mil tres mil, 22, e245.

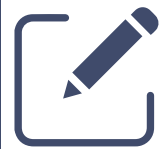

https://doi.org/10.35707/dostresmil/22245

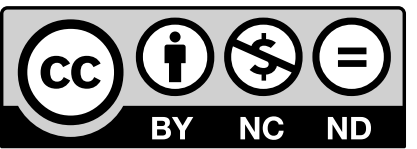

"Experto en Derecho Penal Empresarial. Defense Corporate. Chief Ethics Officer (cEo) de la Asociación Colombiana de Derecho Penal Empresarial ASCOLDPEM. 
Resumen. La ética empresarial, desde los años 80, ocupa la mayor atención en las relaciones económicas actuales. Como resultado de la crisis global de 2008, se acentúa la idea de que las empresas implementen códigos de ética en varios sectores: el medio ambiente, las normas de competencia leal, la legislación laboral, la protección a la intimidad, la propiedad intelectual, la lucha contra la discriminación en las empresas, y la corrupción, entre otros sectores.

Abstract. Business ethics, since the 80s, occupies the most attention in current economic relationships. As a result of the 2008 global crisis, the idea that companies implement codes of ethics in various sectors is accentuated: the environment, fair competition rules, labor legislation, privacy protection, intellectual property, fight against discrimination in companies, and corruption, among other sectors.

Palabras claves

Corrupción, compliance, ética empresarial, Proyecto Hoowarr, autorregulación, legitimidad, bien común, cambio de paradigma, hipermoderno, Corporate Compliance, certificaciones.

Key words

Corruption, compliance, business ethics, Hoowarr Project, self-regulation, legitimacy, common good, paradigm shift, hypermodern, Corporate Compliance, certifications. 


\section{Compliance program}

El origen de estos programas de cumplimiento se ubica en Estados Unidos de Norteamérica, en la primera mitad del siglo pasado, en un contexto marcado por las tensiones entre dos extremos: por un lado, la desconfianza hacia el poder empresarial y, por el otro, la creencia de que la autorregulación empresarial es más efectiva que la regulación estatal (Gallego, 2014).

Normativas internacionales como el estándar global anticorrupción Iso 37001 español, la UK Bribery Act o la US Foreign Corrup Practices Act 1977, establecen su aplicación más allá de sus fronteras. Ergo, las empresas españolas, británicas o americanas exigen a las empresas de otros países que tengan compliance program para poder operar con ellas. De ahí que toda empresa colombiana debe tener este programa.

La ética empresarial surge a partir de los años 80 como consecuencia de los escándalos económicos y financieros, mayormente acentuados con la crisis económica mundial de 2008, consecuencia directa de la dinámica de la economía informacional global, y el resultado de factores como la liberación y la desregulación de mercados, además de las instituciones financieras que permitieron la cuasilibre circulación de capital en las empresas y en todo el mundo (Castells, 2013).

El resultado de la crisis global de 2008 deja como característica principal en el poderoso sistema financiero, la llamada "privatización del futuro" (Castells, 2013, p. 401). A partir de esa época, las empresas se aventuraron por consagrar códigos de ética en varios sectores: el medio ambiente, las normas de competencia leal, la legislación laboral, la protección a la intimidad, la propiedad intelectual, la lucha contra la discriminación en las empresas, la corrupción, etc. Con la OCDE, en 1997, se establece como ilegal el pago de soborno transnacional y recomienda a todos sus países miembros que así lo prohíban.

El compliance debe estar fundamentado en varios pilares: que esté al servicio del hombre, que sea dentro de la legitimidad y basado en la ética ${ }^{1}$. El compliance es un derecho fundamental. Todo esto porque el poder de la empresa en los tiempos hipermodernos es tan grande que está por encima de todo.

De tal suerte que la función del compliance es legislar para la empresa, se convierte en su legislativo, con basamento en su norma superior que es el código de ética. Así el compliance de una empresa será legítimo, si la empresa sirve a los derechos humanos, y a los valores fundamentales de la sociedad democrática. El tema de fondo es que el protagonismo de la empresa y sus riesgos han estado sometidos a un debate político desde una perspectiva dogmática y ortodoxa (Adam Smith, David Ricardo, Paul Samuelson, Francis Fukuyama, Jagdish Bhagwati, Vandana Shiva, y muchos más), situación que con la ética implica un cambio de paradigma.

${ }^{1}$ A esta conclusión llegaron los más de 2000 líderes que se reunieron en Davos, Suiza (17 al 20 de enero de 2017) en el reciente Foro Económico Mundial que: el liderazgo del siglo xxi se debe sustentar en servicio a los demás, tránsito por la legalidad y conducta ética innegociable. 
El Covid-19 acelera la era de las crisis. Asistimos a una sociedad de crisis, o en crisis. El mundo actual atraviesa profundas crisis: de legitimidad democrática, económica, de liderazgo mundial, de relaciones internacionales, de valores, de buenas prácticas, de la constitución de bienestar, del contrato social, del derecho penal tal como lo conocimos. Un mundo disfuncional dominado por las corporaciones.

Para "salvar el capitalismo, hay que arreglarlo" (Barría, 2019, s.p.). Para salvar el derecho penal tal como lo conocimos con el avance de las nuevas tecnologías, hay que arreglarlo. El Foro Económico Mundial, más conocido como el Foro de Davos, que reúne a los más importantes líderes empresariales y políticos cada año en Suiza, publica el Manifiesto de Davos 2020 (citado por Barría, 2019), que son los principios éticos que deberían seguir las compañías:

1. El propósito de las empresas es colaborar con todos los grupos de interés implicados en su funcionamiento (stakeholders). Significa esto que las empresas no funcionan únicamente para sus accionistas, sino para todas las partes involucradas: empleados, clientes, proveedores, comunidades locales y la sociedad en general.

2. "Una empresa es más que una unidad económica generadora de riqueza" (Citado por Barría, 2019, s.p.). Debe atender a las aspiraciones humanas y sociales en el marco del sistema social en su conjunto.

3. Una empresa multinacional es en sí misma un grupo de interés. La sociedad civil y los gobiernos son grupos de interés, también. Estos grupos de interés están al servicio del futuro global.

Dichos principios éticos requieren de políticas correctas. Por tal motivo, del concepto de política que se tenga será así mismo el concepto del derecho penal de las empresas que admitamos y desarrollemos. Todo porque:

El derecho penal expresa de modo más intenso que otras materias jurídicas la soberanía nacional, soberanía a la que sólo se renuncia con disgusto, aunque esta renuncia sea meramente parcial, y de este modo - al menos en amplios sectores- el derecho penal se presenta como un derecho político. (Tiedemann, 1998, p. 3).

\section{Colombia y la OCDE}

El día viernes 25 de octubre de 2013, Colombia protocoliza el ingreso formal a la Organización para la Cooperación y el Desarrollo Económico (OCDE). El mencionado ingreso fue aprobado el 19 de septiembre de 2013, y el 30 de mayo de 2018 es aceptada como miembro de la ocDE. Sin embargo, apenas este 21 de octubre de 2019, la Corte Constitucional declara exequible la norma que reglamenta el ingreso del país a la Organización para la Cooperación y el Desarrollo Económico (OCDE), quedando pendiente estudiar la Ley de Privilegios e Inmunidades que dicta las reglas de las misiones diplomáticas que operen en el país. Finalmente, el 28 de abril de 2020, en plena pandemia, Colombia se convierte formalmente en el país número treinta y siete 
en ser miembro de la OCDE, siendo el tercero en América Latina y el Caribe, junto a Chile y México. La idea fundamental es sin duda que Colombia trabaje para que sus políticas se ajusten a las de la OCDE, que hasta ahora solo son compromisos. Es inadmisible que Colombia sea miembro del club de las buenas prácticas o de los ricos, mientras niños se mueren de hambre en La Guajira.

El diálogo para que Colombia sea miembro de la OCDE versó sobre inversiones, seguros y pensiones privadas, gobernanza pública, política regulativa en educación, salud, empleo, entre otros, y como dijimos en líneas anteriores, la exigencia obligada de la responsabilidad de las personas jurídicas, que recomendamos sea penal, como lo expresa el Proyecto Hoowarr (Ruíz, 2017) sobre una responsabilidad penal de las personas jurídicas en Colombia. Sumado está el proyecto del Gobierno (archivado) del presidente de Colombia, Iván Duque: "Por la cual se adoptan medidas para promover la probidad administrativa, combatir la corrupción, establecer la responsabilidad penal de las personas jurídicas, fortalecer el Ministerio Público y se dictan otras disposiciones" (Proyecto de Ley No 117 de 2018), concretamente capítulo V, título V del Proyecto, por cierto, mal redactado porque hay un título contenido en un capítulo, debería ser al contrario.

A renglón seguido, para la elaboración de un programa de cumplimiento se puede recurrir a la Guía expedida por la Superintendencia de Sociedades de Colombia, mediante Circular externa 100-000003 del 26 de julio de 2016 para programas de cumplimiento para la prevención de las conductas previstas en el artículo 2 de la Ley 1778 de 2016, y además se tengan en cuenta los siguientes documentos: 1. El modelo de la empresa Fullsix Italia. 2. El organismo especializado en control interno o Committee of Sponsoring Organizations of the Treadway Comission (coso). 3. La U. S. Federal Sentencing Guidelines for Organizations. 4. La sarbanes-Oxley Act 2012, The Bribery Act 2010 (rige en el Reino Unido en marzo de 2011). 5. El modelo de Corporate Governance cuyo origen es en Estados Unidos pero impulsado por la OCDE, que reúne aspectos relacionados con la prevención y la sanción de delitos, recogidos en códigos éticos y de conducta. 6. La Responsabilidad Social Empresarial o RSE, que en las últimas décadas ha tenido acogida, y consiste en un modelo de negocios fundado en valores corporativos, en la transparencia, accountabilty y anticorrupción, aplicables a todas las áreas de la empresa. 7. Decálogo de medidas de prevención en materia penal dirigido a las empresas, elaborado por Transparencia Internacional España, decálogo que contiene "los principios de transparencia y prevención de la corrupción para las empresas”, elaborado por Silvina Bacigalupo en mayo de 2012.

Por medio de la Resolución n. ${ }^{\circ}$ 100-002657 del 25 de julio de 2016, la Superintendencia de Sociedades establece los criterios de un Programa de Transparencia o de Ética Empresarial, de conformidad con el inciso 2 del artículo 23 de la Ley Anticorrupción de 2016. Los requisitos son:

1. Ser una sociedad vigilada por la Superintendencia de Sociedades.

2. Que en el año inmediatamente anterior haya realizado negocios de cualquier naturaleza, de forma habitual, con personas naturales o jurídicas extranjeras, públicas o privadas.

¡El compliance llegó para quedarse! 
3. Que los negocios o transacciones internacionales sean realizados por una sociedad colombiana del sector farmacéutico, de infraestructura y construcción, manufactura, minero-energético, o de tecnología de la información y comunicaciones, a través de un tercero que puede ser contratista, intermediario, o sucursal, por sectores, de acuerdo con sus ingresos brutos, activos totales o empleados, especificados en la resolución precitada. Así:

3.1. Sector farmacéutico: Que haya obtenido ingresos brutos iguales o superiores a 75000 salarios mínimos mensuales legales vigentes, que tenga activos totales iguales o superiores a 75000 salarios mínimos mensuales legales vigentes, o que disponga de una planta de personal igual o superior a 2000 empleados directos.

3.2. Infraestructura y construcción: Que haya obtenido ingresos brutos iguales o superiores a 150000 salarios mínimos mensuales legales vigentes, que tenga activos totales iguales o superiores a 150000 salarios mínimos mensuales legales vigentes, o que disponga de una planta de personal igual o superior a 2000 empleados directos.

3.3. Manufacturero: Que haya obtenido ingresos brutos iguales o superiores a 150000 salarios mínimos mensuales legales vigentes. Que tenga activos totales iguales o superiores a 150000 salarios mínimos mensuales legales vigentes, o que disponga de una planta de personal igual o superior a 2000 empleados directos.

3.4. Minero-Energético: Que haya obtenido ingresos brutos iguales o superiores a 150000 salarios mínimos mensuales legales vigentes. Que tenga activos totales iguales o superiores a 150000 salarios mínimos mensuales legales vigentes, o que disponga de una planta de personal igual o superior a 2000 empleados directos.

3.5. Tecnologías de la información y comunicaciones: Que haya obtenido ingresos brutos iguales o superiores a 500000 salarios mínimos mensuales legales vigentes. Que tenga activos totales iguales o superiores a 500000 salarios mínimos mensuales legales vigentes, o que disponga de una planta de personal igual o superior a 1000 empleados directos. (Resolución n. ${ }^{\circ}$ 100-002657 del 25 de julio de 2016. Superintendencia de Sociedades).

\section{Los compliance que debe tener toda empresa}

Toda empresa debe diseñar, implantar y contar con auditorías de sistemas de gestión del cumplimiento. Para lograr este cometido requiere como mínimo: 1) Compliance penal, si en el país se regula la responsabilidad penal de las personas jurídicas; 2) Corporate Compliance que regula el sistema de gestión compliance; y 3) un sistema anticorrupción, que regule el sistema de gestión antisoborno. No son los únicos, por lo cual la empresa debe implantar otros sistemas que implican gestión del riesgo.

\section{4. ¿Qué empresa se ha llevado mi queso? Buscando respuestas en el laberinto de la responsabilidad penal de las empresas en Colombia}

Retomo las aportaciones de Spencer Johnson (1998) con su obra: ¿Quién se ha llevado mi queso?, porque en medio del debate de admitir o no la responsabilidad penal de las personas jurídicas en Colombia, es esta la obra que mejor encaja en la reflexión y aporte de ideas válidas en torno a la noción de cambio de paradigma, como la necesidad de enfrentarse a ese cambio y anticiparlo. 
La metáfora del laberinto y el queso en la política en los tiempos actuales debe ser reformulada. Hablar de política criminal en Colombia en estos momentos, es unificar que las reglas del juego alternativas van más allá de extremos o ideologías: una política diferente. Esta es la buena noticia. La mala, que seguimos atrapados en la ligera idea de posturas arcaicas, dogmáticas, que no enfrentan la realidad ni siguen criterios de política criminal hipermoderna.

Estamos construyendo la política colombiana con base en historia ya superada o al menos poco investigada. Cuando la política se convierte en un fin en sí mismo, queda al servicio de las ideologías y se vuelve poco practicable, el más de lo mismo. Hay tres elementos fundamentales en cualquier política diferente: legitimidad, ética y servir a la comunidad. La legitimidad de la política es que sirva a los derechos humanos y a los valores fundamentales de cualquier comunidad democrática. El nuevo paradigma de la política es la ética, una política ética. Nace una nueva política criminal basada en la ética: Nueva política criminal ética.

Existe un miedo generalizado de la gente por apoyar una u otra postura de admitir la punición de las empresas. Visualizo que curiosamente se hace política criminal aún con dogmatismo, que impera en cada uno de los debates. La política criminal supera en creces a la dogmática. El infausto futuro de la dogmática viene aupado por la política criminal de nuevo cuño en los tiempos hipermodernos. ¿Qué queda de la política criminal en Colombia? Después de tantos ires y venires a lo largo de la democracia representativa, con el más de lo mismo, no queda otro camino que acoger el programa penal más ético posible.

Desde que agitamos la discusión de la cuestión de la responsabilidad penal de las personas jurídicas en Colombia, hace ya más de una década, no he visto discusión alguna sobre la ética en las propuestas negativas. Las propuestas no son un fin en sí mismas, ni tampoco son contrarias al progreso de Colombia, como puede entenderse de cada una de estas. El debate no es de izquierda o derecha, o de centro-derecha, ni de escuelas, de libre comercio o de proteccionismo, sino de comercio ético (Felber, 2018), de propuesta ética y no ética al regular la responsabilidad penal de las personas jurídicas en Colombia. La ética lo es todo en cualquier transformación de la sociedad real. ¿Quién se muestra contrario a la libertad, el comercio, las ayudas, la transparencia, el progreso, el controlar a las empresas como actor racional que busca maximizar su beneficio a través de la corrupción?, creo que nadie, pero hasta ahora el enfrentado debate es teórico.

El tema debe focalizarse en saber cuál es el control más eficaz para combatir la corrupción. Cualquier postura debe hacerse desde el uso de la política predictiva pero no como fin en sí mismo, para tratar de comprender la realidad mirando el pasado y el presente para predecir el futuro que permita anticipar decisiones ahora. El futuro es ya, tomorrow is now. Hay que hacer el futuro, no se trata de solo predecir, hay que hacer.

Cuando se anticipan decisiones se está haciendo futuro. Otros dirán que es la filosofía de la anticipación. La política criminal debe dejar su verticalidad para convertirse en una razón transversal. Todo cambia, no podemos quedarnos atados a un pasado dogmático, hay que 
adaptarnos a la nueva realidad. Una propuesta ética será reforzar y patrocinar la creatividad, que es la mejor manera de mirar el futuro. Si hay que cambiar los fundamentos de la teoría del delito en Colombia para resolver el problema de las empresas y su criminalidad, está bien, porque el derecho penal es un solucionador de problemas. Debemos desaprender muchas cosas de la política criminal tradicional y aprender otras nuevas. Hay que recordar que el objeto, el método y la legitimación del derecho penal han sido trasladados de forma indefectible a la política criminal. Todos somos constructores. La punición de las empresas, por tanto, es una cuestión de política criminal, no atiende a razones dogmáticas que fijadas en criterios antropocéntricos, las hace inviables. No es un problema de acción, sino de responsabilidad.

El mundo es otro. El individuo ha muerto. Asistimos a un mundo corporativo. Para nadie es un secreto la existencia actual del poder corporativo y que el nuevo comerciante en los tiempos actuales son las empresas transnacionales. Con razón anota Christian Felber que:

El poder de las empresas y sus lobbies es ahora tan grande, que en derecho internacional se tiende a anteponer el derecho mercantil (incluida la protección de inversiones y de patentes) a los derechos humanos, la protección del medio ambiente y del clima, la diversidad cultural o los objetivos de distribución, amenazando incluso con derogarlos. (Felber, 2018, p. 13).

El mundo es pragmático, sin ser un fin en sí mismo. Recordamos las frases del Quijote a Sancho en el capítulo Carta de Don Quijote de la Mancha a Sancho Panza, gobernador de la ínsula Barataria: "No hagas muchas pragmáticas; y si las hicieres, procura que sean buenas y, sobre todo que se guarden y cumplan; que las pragmáticas que no se guardan lo mismo es que no lo fuesen" (Cervantes, 1966, s. p.). De ahí que cualquier ente que tenga que ver con el desarrollo de un/unos derecho/s fundamental/es debe ser sujeto de atribución de responsabilidad penal, como por ejemplo los partidos políticos que en España ya lo son con la Ley 7 de 2012.

\section{Las certificaciones}

Sea lo primero decir que asistimos a un mundo de certificaciones corporativas. De ahí que hay un movimiento universal de certificaciones laborales, el que cada vez se convierte en un proceso común. Ser un profesional u empresa certificada constituye una ventaja. En Colombia, el proceso de certificaciones está lento. Nuestra misión es renovar, reinventar en este estadio. Y las corporaciones que quizás las tengan, es más por obligación que por voluntad. La apuesta debe ser por reputación, por buenas prácticas, por razones éticas.

Una certificación es una medida del nivel de competencia y garantía de idoneidad, es saber que el producto ofrecido a la comunidad es bueno, y que las personas saben hacer lo que dicen hacer. Tanto en el sector privado como en el público, que ha dado pie a hablar de un public compliance.

El establecimiento de un programa de cumplimiento, de seguro permitirá seleccionar empleados no por experiencia acumulada, sino por competencia. También permite aprovechar la mano de obra del adulto que muchas veces es descalificado por ser considerado un desactualizado.

iEl compliance llegó para quedarse!

Qué debe saber el empresario acerca del programa de cumplimiento y el poder corporativo 


\section{El compliance como necesidad de buen gobierno y ética en las empresas}

Existen dos temas grandes en esta etapa hipermoderna: la gobernanza y lo corporativo. En una y otra, lo fundamental es la toma de decisiones. Estas decisiones deben estar cargadas de honestidad y transparencia.

En algunos países, la no transparencia arredra una responsabilidad penal de las personas jurídicas, autónoma e independiente de sus órganos de administración y de dirección. Colombia admite la responsabilidad administrativa de las personas jurídicas con la Ley 1778 de 2016 del 2 de febrero, pero está en mora de adoptar una responsabilidad penal de las empresas, como lo venimos planteando y mucho antes que la Procuraduría General de la Nación.

Mencionamos nuestro Proyecto Hoowarr sobre una responsabilidad penal de las personas jurídicas, que es el primer proyecto completo sobre esta temática en Colombia. De tal suerte, que podemos afirmar con causticidad y vehemencia que la ética en las empresas y el buen gobierno corporativo constituye el tema central y de gran demanda creciente en la sociedad. Ergo, el compliance es la herramienta más eficaz para el cumplimiento normativo en cuanto a que la empresa a través de su officer o responsable del cumplimiento (compliance officer) elabore un programa que identifique y evalúe los riesgos operativos y legales, para las buenas prácticas, en una sociedad cada vez más compleja y global. Debemos reconocer que uno de los profesionales que con mayor solvencia puede tratar el tema del compliance y satisfacer las exigencias de prevención de riesgos penales, es el abogado penalista. Es el referente profesional indiscutible para asumir las obligaciones de cumplimiento. El oficial de cumplimiento es el "Pepe Grillo" de la empresa.

Se acentúa la cultura corporativa. Las corporaciones tienen la misión del Desarrollo Económico Sostenible (las $5 \mathrm{P}$ de la onU) y el respeto por los derechos humanos (como los principios de Ruggie): proteger, respetar y remediar (Bilchitz, 2010) en los últimos tiempos. Del mismo modo, un compliance público acentúa una buena gobernanza y traslada una eficaz democracia transparente.

La idea es que todas las entidades públicas adopten un programa de cumplimiento, por ende, tener un oficial de cumplimiento idóneo. Es bueno advertir que el compliance sea eficaz y no un paper compliance, o un papel mojado. De esta manera, el funcionamiento de las entidades públicas apuntala mayor transparencia.

\section{Referencias}

Barría, C. (2019, 5 de diciembre). Qué es el Manifiesto de Davos 2020 y cómo pretende transformar el capitalismo. BBC News Mundo. Recuperado de https://www.bbc.com/mundo/noticias-50652715

Bilchitz, D. (2010, junio). El marco Ruggie: ¿Una propuesta adecuada para las obligaciones de derechos humanos de las empresas? SUR-Revista Internacional de Derechos Humanos, (7) 12, pp. 209-241. Recuperado de http://www.corteidh.or.cr/tablas/r26672.pdf

iEl compliance llegó para quedarse! 
Castells, M. (2013). Después de la crisis (Trad. Fernández Bobrovski, D.). Madrid, España: Alianza Editorial.

Cervantes Saavedra, M. (1966). El ingenioso hidalgo don Quijote de La Mancha. Madrid, España: Espasa-Calpe. Recuperado de https://cvc.cervantes.es/literatura/clasicos/quijote/edicion/parte2/cap51/ cap51_02.htm

Colombia. Proyecto de Ley n. ${ }^{\circ} 117$ de 2018, "por la cual se adoptan medidas para promover la probidad administrativa, combatir la corrupción, establecer la responsabilidad penal de las personas jurídicas, fortalecer el ministerio público y se dictan otras disposiciones". Recuperado de https://www.procuraduria.gov.co/portal/media/file/TEXTO\%20COMPLETO\%20PROYECTO\%20DE\%20LEY.pdf

Colombia. Superintendencia de Sociedades. Resolución n. ${ }^{\circ}$ 100-002657 del 25 de julio de 2016, "por la cual se establecen unos criterios de acuerdo con el inciso $2 .^{\circ}$ del artículo 23 de la Ley 1778 de 2016". Recuperado de http://forvm.com.co/wp-content/uploads/2016/08/Resoluci\%C3\%B3nN\%C3\%BAmero-100-002657-de-25-07-2016.-Superintendencia-de-Sociedades..pdf

España. Ley Orgánica 7/2012, de 27 de diciembre. Por la que se modifica la Ley Orgánica 10/1995, de 23 de noviembre del Código Penal en materia de transparencia y lucha contra el fraude fiscal y en la Seguridad Social. Recuperado de https://www.boe.es/diario_boe/txt.php?id=BOE-A-2012-15647

Felber, C. (2018). Por un comercio mundial ético. Porque el debate no es entre libre comercio y proteccionismo, sino entre comercio ético y no ético (Trad. Yusta, S.). Barcelona, España: Ediciones Deusto. Recuperado de https://planetadelibrosco0.cdnstatics.com/libros_contenido_extra/38/37148_Por_ un_comercio_mundial_etico.pdf

Gallego Soler, J. I. (2014). Criminal compliance y proceso penal: Reflexiones iniciales. En AA. VV. Responsabilidad de la empresa y Compliance (pp. 195-272). Madrid, España: Edisofer, B de F.

Johnson, S. (1998). Who moved my cheese [¿Quién se ha llevado mi queso?]. G.P. Nueva York: Putnam’s Sons.

Ruiz Rengifo, H. W. (2017). Proyecto Hoowarr sobre responsabilidad penal de las personas jurídicas en Colombia. Ibáñez-ASCOLDPEM. Recuperado de https://asosec.co/wp-content/ uploads/2017/05/955334952_proyecto_hoowarr.pdf

Tiedemann, K. (1998). L'europeizzazzione del diritto penale en Rivi. (Trad. de Bernardi A., V.) Milano, It, di Diri., e Proc., Nuova Serie, anno XLI. 